\title{
MULHERES NA POLÍTICA: A PRESENÇA DAS CANDIDATAS A DEPUTADA FEDERAL DO PARANÁ NA PROPAGANDA ELEITORAL TELEVISIVA DE 2014
}

\author{
Womans in politics: the presence of Parana' 's female candidates on the 2014 \\ electoral advertising on $T V$
}

Mujeres en la politica: la presencia de las candidatas al Congreso Federal de
Paraná en la propaganda electoral en la televisión en 2014

Camilla Quesada Tavares Professora do Programa de Pós-Graduação em Comunicação da Universidade Federal do Maranhão (UFMA). camilla.tavares8@gmail.com

Michele Goulart Massuchin Professora dos Programas de Pós-Graduação em Comunicação e Ciência Política da Universidade Federal do Paraná (UFPR). mimassuchin@gmail.com

\section{Resumo}

O artigo analisa a presença das candidatas ao cargo de deputada federal pelo estado do Paraná no Horário Gratuito de Propaganda Eleitoral (HGPE) de 2014, no Brasil. A partir da implementação da lei de cotas, os partidos são obrigados a apresentar pelo menos $30 \%$ de candidaturas do sexo feminino para disputar a eleição. Mas será que as concorrentes conseguem ter uma equidade na distribuição do tempo de propaganda, quando comparada aos homens? Tendo esta pergunta em vista, o trabalho busca mapear o tempo de aparição destinado a essas candidatas e se há diferenças entre os partidos, observando a eleição mais recente. A metodologia utilizada é a análise de conteúdo quantitativa e os resultados indicam que as mulheres ainda são sub-representadas na propaganda eleitoral, embora essa diferença tenha diminuído comparada a eleições anteriores.

Palavras-chave: Horário eleitoral. Candidaturas femininas. Eleições 2014.

\section{Abstract}

The paper analyzes the presence of female candidates for the positions of Federal and State Deputies of Paraná in the 2014 free electoral advertising on television, in Brazil. Since the implementation of the quotas law, parties are required to submit at least $30 \%$ female candidates to run the election. But do women competitors have an equal distribution of advertising time when compared to men? With this question in view, the paper seeks to map the time of appearance intended for these candidates and identify if there are differences between the parties, observing the most recent election. The methodology used is the quantitative content analysis and the results indicate that women are still underrepresented in 
the electoral advertising, although this difference has diminished compared to previous elections.

Keywords: Electoral advertising. Female candidates. 2014 election's.

\section{Resumen}

El artículo analiza la presencia de las candidatas al cargo de diputada federal de Paraná en el Horario Gratuito de Propaganda Electoral (HGPE) de 2014, en Brasil. A partir de la implementación de la ley de cuotas, los partidos están obligados a presentar al menos el 30\% de candidaturas femeninas para disputar la elección. Pero, ¿las mujeres logran tener una equidad en la distribución del tiempo de propaganda, en comparación con los hombres? Con esta pregunta, el trabajo busca mapear el tiempo de aparición destinado a esas candidatas y si hay diferencias entre los partidos, observando la elección más reciente para diputados. La metodología utilizada es el análisis de contenido cuantitativo y los resultados indican que las mujeres todavía están con baja representatividad en la propaganda electoral, aunque esta diferencia ha disminuido en comparación con las elecciones anteriores.

Palabras clave: Horario electoral. Candidaturas feminina. Elecciones 2014.

\section{INTRODUÇÃO}

Este artigo analisa a presença das mulheres candidatas à deputada federal do estado do Paraná no Horário Gratuito de Propaganda Eleitoral (HGPE) televisivo de 2014. O objetivo é verificar como se dá essa aparição das mulheres, a fim de identificar as proximidades e diferenças no que concerne à presença masculina, especialmente no tempo de televisão destinado a cada tipo de candidatura. Os estudos sobre gênero - neste caso, sob a ótica da mulher - e política demonstram como é problemática a participação da mulher no campo político, predominantemente masculino (Miguel, 2014). Há uma série de entraves já identificados - como os institucionais, culturais e socioeconômicos (Walby, 1990; Sporh et al, 2016) - que dificultaram a participação da mulher enquanto representante política.

Segundo estudo de Sporh et al (2016), as mulheres representam pouco mais de $20 \%$ do total dos parlamentares eleitos ao redor do mundo. No Brasil, a representatividade feminina na Câmara dos Deputados aumentou nas eleições de 2018. O número de parlamentares mulheres cresceu de 51 para 77, um crescimento de 51\% em relação a 2014. As deputadas correspondem a $15 \%$ do total de cadeiras da Câmara, contra $10 \%$ que totalizavam na eleição anterior (Biroli; Miguel, 2014). Apesar desse avanço, há ainda grande descompasso entre o número de homens eleitos e o de mulheres - Amazonas, Maranhão e Sergipe, por exemplo, não elegeram nenhuma deputada federal -, e apenas um estado brasileiro será governado por uma mulher nos próximos quatro anos, o do Rio Grande do Norte. Mesmo após a implementação da lei de cotas, que visa incentivar a participação feminina nas disputas 
eleitorais, os resultados ainda estão longe de serem efetivos, especialmente no Brasil (Spohr et al, 2016).

Tendo este cenário em vista, é preciso incentivar não só a participação da mulher nas eleições, mas também oferecer subsídios que aumentem suas chances de serem eleitas. No período eleitoral, uma das formas de fazer isso é garantindo o acesso qualificado ao rádio e à TV por meio do horário eleitoral. Apesar do avanço da campanha online, o HGPE constitui-se ainda como espaço central de disputa da preferência do eleitor, principalmente para cargos da eleição proporcional, já que apresenta, de modo condensado, os candidatos de cada partido. Torna-se relevante, portanto, saber qual o lugar que as candidatas ocupam neste ambiente de campanha.

\section{MULHERES, POLÍTICA E ELEIÇÕES}

A discussão sobre a baixa presença feminina nas instâncias de representação política data do final do século XX (Araújo, 2001). A partir dessa constatação, vários estudos no âmbito da ciência política tentam buscar respostas para as possíveis barreiras que permanecem, mesmo após a implementação da política de cotas em alguns países, como é o caso do Brasil. A participação mínima da mulher nas disputas por cargos eletivos foi efetivada na política brasileira em contexto nacional em 1997, a partir da Lei $\mathrm{N}^{\circ}$ 9.504, que estabelece normas para as eleições. No entanto, a obrigatoriedade de cumprimento da cota de gênero passou a ser exigida somente a partir da Lei $\mathrm{N}^{\circ}$ 12.034, de 29 de setembro de 2009. De acordo com o disposto, do número de vagas disponíveis, cada partido ou coligação deve preencher o mínimo de $30 \%$ e o máximo de $70 \%$ para candidaturas de cada sexo. Na prática, o que se pretende é incentivar a participação das mulheres nas eleições, já que o número de candidatos homens é predominante em praticamente todos os pleitos ${ }^{1}$.

A partir de um levantamento feito em 21 países por Norris (2013), observa-se que, na média, a política de cotas de gêneros é efetiva. Com exceção do Chile, Colômbia e Uruguai, os demais países sul-americanos adotam essa política ${ }^{2}$ e é possível verificar que houve um aumento da representação feminina nos parlamentos sul-americanos nos últimos dez anos,

1 De acordo com dados do Tribunal Superior Eleitoral (TSE), só nas eleições de 2014 o número de candidatos masculinos ao Senado foi de 131 contra 34 mulheres que disputaram o pleito; para deputado federal, foram 4.153 homens e 1.724 mulheres; por fim, dos 10.160 candidatos que concorreram para deputado estadual, apenas 4.161 eram mulheres.

2 Segundo Martins (2007), Chile e Uruguai adotam cotas voluntárias em alguns partidos políticos. Já a Colômbia não possui nenhum tipo de política de incentivo com essa finalidade. 
embora a proporção ainda seja baixa na maior parte deles, como é o caso do Brasil. Bolívia e Equador integram as exceções, já que possuem percentuais acima de 40\%. A Bolívia, no entanto, é o único país onde há equidade na representação. Em 2015, além de apresentar a menor diferença de proporção entre homens e mulheres na história do parlamento, o país elegeu a primeira mulher presidente da Câmara de Deputados.

Apesar de instituída há quase 20 anos no Brasil, o que se observa é que o número de representantes femininas eleitas ainda é muito baixo. Na atual legislatura (2015-2018), dos 81 senadores, apenas 13 são mulheres. A mesma disparidade é observada na Câmara dos Deputados, onde, atualmente, apenas 44 das 513 cadeiras são ocupadas por representantes femininas (Spohr et al, 2016). Araújo e Alves (2007) sugerem que existem diversas barreiras que impedem o aumento da participação do público feminino na política, mesmo com as cotas de sexo. Há os fatores históricos e sociais, como o insulamento na vida doméstica, a dupla jornada de trabalho e a construção social da política como esfera masculina (Miguel, 2014), mas também os institucionais, como o sistema partidário (lista aberta, fechada ou misto), tipo de sistema eleitoral (proporcional e majoritário) e tamanho do distrito (Araújo; Alves, 2007). Araújo e Alves (2007) colocam, ainda, que é preciso entender o papel das mulheres dentro dos partidos, como seu tempo de filiação e trajetória, antes de disputar um cargo eletivo.

Neste sentido, Barbosa (2015) identifica que as mulheres são sub-representadas no interior das executivas partidárias estaduais. Ou seja, ainda há poucas mulheres entre os dirigentes dos partidos. $\mathrm{O}$ autor constata que os partidos de esquerda foram os principais responsáveis pela presença feminina, sendo o PT o que mais recrutou mulheres, chegando a 30\% em 2014 (Barbosa, 2015). Outros, como PP e DEM, apresentam 16\% e 13\% respectivamente, enquanto que o PMDB possui apenas 5\% de mulheres entre seus dirigentes. Os resultados vão ao encontro de vários estudos presentes na literatura, citados por Araújo e Alves (2007), que constatam que partidos de esquerda tendem a estimular e ampliar as chances de eleição de mulheres.

Os dois últimos fatores - os institucionais e o papel que as mulheres ocupam dentro dos partidos - são importantes para conhecer o que está por trás dessa candidatura. Em muitos casos verifica-se o recrutamento de candidatas com quase nenhuma trajetória política, que apenas oferecem seus nomes para que a legislação seja cumprida pelos partidos. Em outros casos, as mulheres possuem algum tipo de relação com homens envolvidos na política, o que indica que elas apenas se utilizam do capital político construído pelo pai, marido ou avô, sem que tenha uma trajetória e capital próprio. Esses fatores implicam, em certa medida, em 
candidaturas femininas que não representam de fato as pautas feministas - como liberdade sexual e direito ao corpo -, deixando em aberto o que se espera da atuação dessas mulheres caso sejam eleitas (Sarmento, 2017).

Os desafios que as mulheres precisam enfrentar na questão política são mais amplos do que a própria representação nas instâncias democráticas. A baixa presença feminina nos espaços públicos de decisão é resultado de um conjunto de fatores que, historicamente, se coloca como empecilho para a participação da mulher em outras esferas de poder. Isso demonstra que não superamos ainda a sociedade patriarcal, estruturada a partir de padrões que garantem aos homens disporem de tempo e energia que caberiam às mulheres, oprimindo, dominando e explorando-as (Walby, 1990; Biroli, 2018). É devido a isso que os homens possuem maior propensão a participarem da vida pública do que as mulheres, posto que estas possuem diversas outras atribuições no cotidiano familiar que o homem, na maioria das vezes, não tem. Na perspectiva de Biroli (2018), a vida doméstica é um fator importante, embora negligenciado nas teorias democráticas, que limita a atuação feminina na vida pública. Além disso, o papel de uma sociedade patriarcal influencia na hora de pensar que durante toda a tradição política, o Brasil trouxe um papel de chefe de família ao homem e isso o incentiva aos cargos de liderança (Viegas; Faria, 1999), também na esfera política. Essa ideia explica, em partes, o porquê de mulheres que têm apoio ou herança de um homem na política possuírem maiores chances de se elegerem do que aquelas que trilham seus caminhos sozinhas, algo que é possível perceber por meio de exemplos como de Roseana Sarney, exgovernadora do Maranhão e filha do ex-senador José Sarney; e da atual vice-governadora do Paraná, Cida Borghetti - casada com Ricardo Barros, que já foi prefeito, deputado federal, senador, secretário estadual do Paraná e ministro da Saúde, nomeado pelo presidente Michel Temer (PMDB) após o impeachment de Dilma Rousseff (PT).

Em consequência desse contexto histórico-social, grande parte das mulheres não possui visibilidade e capital político como os homens que se candidatam (Sacchet; Speck, 2012), o que não dá a elas chances reais de serem eleitas. Essa diferença entre homens e mulheres acaba transparecendo nos recursos propagandísticos oferecidos pelos partidos, em que os candidatos à reeleição ou ocupantes de cargos não eletivos ganham mais recursos partidários e financeiros, em relação às candidatas que seguem com menos espaço e visibilidade, deixando transparecer novamente que apenas a proporcionalidade é cumprida, mas que efetivamente a campanha não é igualitária entre os concorrentes. 
Ainda que a lei da proporcionalidade das cotas traga a obrigatoriedade do recrutamento de mulheres na sociedade, há uma distância considerável entre a presença na disputa e as chances de eleição, pois existe uma série de barreiras neste processo. Além do baixo recurso financeiro destinado às candidaturas femininas (Sacchet; Speck, 2012), Araújo e Borges (2013) constatam ainda que o perfil da candidata importa, assim como sua posição dentro do partido. De acordo com o estudo dos autores, ao que tudo indica, ter uma trajetória pública, com o exercício de alguma forma de poder, constitui elementos importantes de recursos não financeiros que podem aumentar as chances de elegibilidade (Araújo; Borges, 2013). Nesta lógica, mulheres que se candidatam apenas para cumprir a cota, sem ter alguma trajetória política anterior ou considerável tempo de militância partidária para conseguir apoio efetivo do partido (Araújo; Borges, 2013), tendem a ter maiores dificuldades de serem eleitas.

Embora este estudo não tenha por objetivo analisar o financiamento e a trajetória das candidaturas, ele fornece informações sobre o apoio partidário recebido pelos candidatos e candidatas por meio da distribuição do tempo no HGPE proporcional. A partir disso é possível identificar se há diferenças significativas entre o tempo destinado aos homens e mulheres no HGPE proporcional e na sua visibilidade dentro dos 45 dias de propaganda ${ }^{3}$, comparando, inclusive, com os resultados de Cervi (2011), que analisou a presença das mulheres no HGPE a deputado federal das eleições de 2006, antes da obrigatoriedade de a lei entrar em vigor.

\section{O HORÁRIO ELEITORAL COMO LUGAR DE DESTAQUE DA ELITE POLÍTICA}

As campanhas eleitorais se desenvolvem de maneira diferente dependendo da cultura e do sistema de mídia de cada país (Holtz-Bacha et al, 2012). No Brasil, um dos principais fatores de distinção em relação a outros países é a proibição de qualquer tipo de propaganda eleitoral paga no rádio e na TV, conforme pontua Albuquerque (2004), o que, segundo Miguel (2005; 2010), diminuiria a influência do dinheiro nas campanhas, pelo menos no que concerne ao acesso aos meios de comunicação de massa ${ }^{4}$. Dessa maneira, dada a representatividade no

\footnotetext{
${ }^{3}$ Até as eleições de 2014, a campanha eleitoral tinha duração de 90 dias, sendo que o horário eleitoral era veiculado durante 45 dias. Após a Lei da Mini Reforma Eleitoral, que entrou em vigor em 2015, o período de campanha foi reduzido pela metade, a veiculação do HGPE caiu para 35 dias e os candidatos a cargos proporcionais passaram a não ter mais acesso aos programas em blocos; eles apenas têm direito aos spots, que são transmitidos sem horário fixo, ao longo de toda a programação.

4 Estudos sobre financiamento de campanha apontam para uma forte relação entre produção de campanha e dinheiro, mas não é nosso objetivo neste trabalho entrar nesse debate. O que se pretende mostrar aqui é que, pelo
} 
Legislativo, os partidos/coligações agregam tempo no rádio e na televisão para veicular a campanha eleitoral ${ }^{5}$. A divisão do tempo total fica a cargo do Tribunal Superior Eleitoral (TSE).

No Brasil, há dois sistemas eleitorais nas eleições: o majoritário e o proporcional. No caso dos deputados e deputadas estudados nesta pesquisa, eles estão inseridos no segundo tipo, ou seja, o eleitor pode votar no candidato ou em sua legenda, e os eleitos serão aqueles mais votados dentro do partido, limitado ao número de vagas conquistado, baseado no coeficiente eleitoral. No caso dessas disputas, o número total de candidatos tende a ser muito maior ao número total de vagas, o que necessitaria de um melhor planejamento para distribuir os "recursos de campanha" a todos os concorrentes (Cervi, 2011). Um desses recursos seria a o tempo no horário eleitoral. Como há pouco tempo e muitos candidatos, há grandes chances de que alguns deles não ganhem espaço na televisão ou até mesmo consigam aparecer na propaganda, mas sem espaço de fala. Cervi (2011), a partir de uma pesquisa realizada sobre as eleições de 2006, indicou que as mulheres tinham menos tempo que os homens e que, ao observar os candidatos à reeleição e outros candidatos, também havia discrepância na distribuição do espaço na propaganda televisiva.

O tempo é distribuído pelos partidos, o que confere legitimidade às instituições partidárias, segundo Dias (2005), pois são as lideranças que dividem o espaço entre os candidatos de seu partido ou coligação. Portanto, é o partido que controla o tempo, sendo que a divisão pode ser mais igualitária ou mais hierárquica. Pode-se optar em dar mais tempo a quem tem mais capital político ou dar o mesmo tempo para todos os concorrentes (Cervi, 2011).

A dependência do candidato ao horário eleitoral é variável, segundo características externas à disputa. Massambani e Cervi (2011) apontam que candidatos com presença regional não dependem tanto de tempo na televisão porque possuem outras fontes de visibilidade pública. Albuquerque, Steibel e Carneiro (2008) também defendem que a distribuição do recurso tem impacto distinto, dependo do tipo de candidato. Por exemplo,

menos no acesso aos meios, o dinheiro não tem influência, pois não é permitido comprar quotas no rádio e na televisão.

5 A divisão do tempo é estabelecida pelo TSE e, até as eleições de 2014, era feita da seguinte maneira: um terço do tempo total é dividido igualitariamente entre todos os partidos. O restante - ou seja, 2/3 - é distribuído proporcionalmente ao número de representantes do partido na Câmara dos Deputados. No caso de coligação, o resultado provém da soma do número de representantes de todos os partidos políticos que fizerem parte dela. $\mathrm{Na}$ prática isso significa que quanto maior a coligação entre partidos com representatividade, maior o tempo disponível no HGPE. 
quem tem votos pulverizados tende a precisar mais dos meios de comunicação do que aqueles que possuem base eleitoral em alguma região geográfica específica.

No que diz respeito às mulheres, as candidatas tinham uma tendência a depender mais da exposição de suas imagens no horário eleitoral do que os homens, haja vista que não conseguiam se inserir em espaços anteriores à campanha (Massambani;e Cervi, 2011). Sobre este ponto, Biroli e Miguel (2014) fazem uma crítica aos meios de comunicação, que poderiam garantir uma visibilidade maior, principalmente para aquelas que já possuem carreira política. Os autores argumentam que as mulheres são pouco retratadas e geralmente estão associadas a estereótipos de gênero convencionais.

Entretanto, com a diminuição do período de veiculação do horário eleitoral no rádio e TV, aliada à ascensão das redes sociais como espaços efetivos de campanha, a centralidade do HGPE - assim como dos meios de comunicação de massa, de modo geral - tende a diminuir (Albuquerque; Tavares, 2018). Embora o período analisado neste trabalho seja anterior à nova legislação, que passou a valer a partir das eleições de 2016, vale pontuar que isso não significa que o horário eleitoral perde totalmente sua importância na disputa, mas que é preciso relativizar seu impacto na decisão do eleitor. Todavia, ele representa o espaço tradicional da campanha midiatizada, para onde grande parte do recurso financeiro dos partidos e coligações é destinada (Lima; Alves, 2015). Compreender qual o espaço da candidata mulher nos programas, se ela possui o mesmo tempo que os homens, por exemplo, continua pertinente. Assim, buscamos responder esses questionamentos e observar se esse cenário se alterou em relação aos dados indicados por Cervi (2011).

\section{METOdologia E VARIÁVEIS DE ANÁliSe PARA ESTUdOS SOBRE A PRESENÇA DAS MULHERES NO HORÁRIO ELEITORAL}

Os dados que compõem o corpus desta pesquisa foram coletados pelos integrantes do Grupo de Pesquisa em Comunicação Política \& Opinião Pública da Universidade Federal do Paraná (CPOP/UFPR) e dizem respeito a todos os programas das eleições para deputado federal de 2014 no Paraná. Nesta eleição, havia 288 candidatos disputando as 30 vagas que o Paraná possui na Câmara dos Deputados. A metodologia para coleta de dados é a quantitativa de análise de conteúdo, pois o universo trabalhado é amplo e busca-se identificar padrões entre os resultados (Cervi, 2009), no que diz respeito, neste caso em específico, sobre a presença das candidatas no HGPE. As categorias de análise utilizadas aqui são baseadas no 
trabalho de Figueiredo et al (1997) e Cervi (2011), com destaque para as variáveis que compõem diretamente o estudo: data, presença de fala, sexo, tempo de exposição, partido e número de segmentos.

Os programas do horário eleitoral proporcional são divididos de acordo com a coligação. Dentro de cada parte, reparte-se ainda por segmentos. Entende-se por segmento uma única unidade de análise do HGPE, isto é, um trecho do programa televisivo que possui autonomia discursiva (Albuquerque, 1999). No caso dos programas para cargos proporcionais, essa diferenciação é bem clara, pois se reduz, em boa parte dos casos, a uma aparição de fala completa do candidato, quando este possui fala; ou então apenas sua imagem e número, nos casos sem falas. No caso das eleições de 2014 no Paraná, são 1.878 segmentos em que aparecem algum dos candidatos ${ }^{6}$. As análises são apresentadas no tópico seguinte.

\section{A DISTRIBUIÇÃO DO TEMPO E A PRESENÇA DAS MULHERES NO HGPE PROPORCIONAL}

A tabela a seguir indica, primeiramente, que no Paraná, as 30 cadeiras do legislativo federal foram disputadas por 317 candidatos. Chama a atenção ainda que foram 224 homens $(72,66 \%)$ para 93 mulheres $(27,77 \%)$, o que não atinge nem a proporcionalidade de cotas exigida pela legislação a partir de 2009 - proporção 70\%-30\%. De toda forma, as diferenças emblemáticas para este artigo estão entre a quantidade de mulheres candidatas e o tempo e espaço que elas possuem na televisão, o que está muito abaixo do esperado. O percentual do número de segmentos e tempo em segundos se aproxima, mas ambos estão em 18\%, o que difere das $29,3 \%$ de mulheres disputando o pleito. Portanto constata-se que há uma subrepresentação delas no HGPE.

Tabela 1 - Distribuição dos candidatos por sexo, tempo e segmentos

\begin{tabular}{|c|c|c|c|c|c|c|}
\hline & $\begin{array}{c}\text { Total/ } \\
\text { candidatos }\end{array}$ & $\%$ & $\begin{array}{c}\text { Total/ } \\
\text { Segmentos }\end{array}$ & $\%$ & $\begin{array}{c}\text { Total Tempo } \\
(\mathrm{s})\end{array}$ & $\%$ \\
\hline Homem & 208 & 72,2 & 1544 & 82 & 19070 & 82,04 \\
\hline Mulher & 80 & 27,77 & 334 & 18 & 4176 & 17,96 \\
\hline Total & 288 & 100 & 1878 & 100 & 23246 & 100 \\
\hline \multicolumn{6}{|c|}{ Teste t de média do tempo: Homem: 12,35 segundos /Mulher: 12,50 segundos } \\
T=0,33 e sig 0,737 \\
\hline
\end{tabular}

6 Há outros 70 segmentos que são desconsiderados na análise porque não há presença dos candidatos, mas de lideranças partidárias ou do uso para campanha majoritária. Como o objetivo é ver a diferença entre homens e mulheres candidatos, não foram incluídos. 
O que estes dados indicam é que, ainda que os partidos estejam perto de cumprir a cota da proporcionalidade no que diz respeito à inclusão de mulheres na disputa, o tempo e espaço destinado a elas na propaganda televisiva não segue a mesma lógica. Há uma preferência pelos candidatos do que pelas candidatas para que apareçam no HGPE proporcional. Enquanto as mulheres dividem $18 \%$ do tempo e do número de segmentos, os homens ocupam $82 \%$. Essa discussão sobre a presença feminina não só para cumprimento da exigência da legislação eleitoral, mas para que efetivamente tenham capacidade de ser eleitas, também dialoga com a trajetória dos candidatos. Cervi (2011) mostrou que mais do que um problema de gênero, há uma diferença entre candidatos à reeleição e os demais. Como as mulheres geralmente não são candidatas à reeleição, raramente conseguem mais tempo, já que esse é um fator preponderante na definição de quem ocupa ou não espaço na propaganda (Cervi, 2011).

Dessa forma, o HGPE parece não se colocar como um espaço para dar visibilidade ou para democratizar, de fato, a esfera política no que diz respeito à inserção feminina. Serve mais como um espaço a ser ocupado pelos candidatos que possuem prioridade: os que já estão na política. Ao fazer isso, ele se torna um mecanismo pouco democrático, já que das 93 candidatas, somente 58 apareceram pelo menos uma vez no HGPE.

Outro dado, no entanto, que chama a atenção é que homens e mulheres têm um tempo médio de exposição muito similar. Ou seja, os que possuem tempo de TV, sejam eles homens ou mulheres, têm um tempo médio semelhante, como indica o teste $t$ de independência de média, que assegura não haver diferenças entre as médias de tempo de homens e mulheres, sendo não significativo (0,737). São 12,35 segundos de média para os homens e 12,5 para as mulheres, ambos com um desvio padrão semelhante, no que diz respeito à duração dos segmentos. Deste modo, ainda que haja diferenças na quantidade total de tempo destinado às mulheres, quando estas conseguem aparecer, o tempo médio dos segmentos no qual elas aparecem tende a ser semelhante ao dos homens, com uma variação também parecida. $\mathrm{O}$ que o dado tende a indicar é que há uma resistência dos partidos quanto à disponibilização ou não do espaço, mas quando este passa a ser ocupado pelas mulheres, elas acabam tendo um tempo semelhante, em média.

Esta informação já indica algumas mudanças quanto aos dados apresentados por Cervi (2011). O autor observou em sua análise que, além da sub-representação no quesito percentual de tempo destinado às mulheres em relação ao percentual de mulheres na disputa, havia uma diferença na média de tempo entre os sexos para os que apareciam na propaganda. Agora os 
dados mostram ainda essa sub-representação, mas quando as mulheres aparecem, elas têm uma média de tempo semelhante.

De modo a complementar à análise, também é interessante observar as diferenças entre os partidos. O intuito é saber se em alguns partidos as mulheres são mais bem representadas ou se a maneira como aparecem é semelhante entre todas as legendas, independente do posicionamento no espectro ideológico. O primeiro dado relevante a ser destacado aqui é que alguns partidos - PP, DEM, PR, PHS, SD, PMN e PROS, ainda que tivessem mulheres candidatas, não deram espaço a elas na televisão. O DEM, por exemplo, não tinha nenhuma candidata na disputa, inclusive, desobedecendo a lei da cota mínima - o que é curioso, já que DEM, junto com o PP, é um dos partidos que adotam mecanismos em seus estatutos para ampliar a participação feminina, conforme aponta Barbosa (2015).

Por outro lado, PCB e PSTU deram visibilidade exclusiva às mulheres em todo o tempo de televisão, com o total de 18 segmentos cada um e com médias de tempo superior a 30 segundos. No caso do PCB, o partido tinha apenas uma mulher concorrendo ao cargo (Prof. Silvina), que ocupou 18 segmentos e totalizou 592 segundos de aparição, sendo a mulher que mais ganhou visibilidade na propaganda televisiva de modo geral. O mesmo ocorreu com o PSTU, que só tinha uma mulher concorrendo ao cargo e deu a ela maior visibilidade: também apareceu em 18 segmentos e obteve 554 segundos, sendo a segunda mulher que mais ganhou visibilidade nos programas televisivos de 2014.

Os demais partidos - 22, no total - distribuíram o tempo entre candidatos e candidatas de modo distinto, em sua maioria. A análise mostra que partidos como PSOL, PT e PDT dividiram o tempo mais igualitariamente entre homens e mulheres. A diferença tanto de número de segmentos ou segundos é muito menor em relação ao PSD, PTdoB, PTB, PRB, PSC, PPS, PEN, PMDB, PSDB, PRTB, PSB e PV, por exemplo, o que reitera a ideia de que partidos mais à esquerda do espectro ideológico tendem a incentivar a participação feminina no âmbito político (Araújo, 2001; Norris, 2013; Barbosa, 2015). O PSDB, por exemplo, tinha apenas uma candidata, mas mesmo sendo um partido com bastante tempo de televisão, destinou somente 178 segundos a ela, colocando-a como a quinta mulher com maior destaque entre as 58 que apareceram durante toda a propaganda e de todos os partidos.

Tabela 2 - Proporção de segmentos e tempo no HGPE entre sexo

\begin{tabular}{|c|c|c|c|c|c|c|c|c|c|c|}
\hline & \multicolumn{4}{|c|}{ Homem } & \multicolumn{3}{c|}{ Mulher } & \multicolumn{2}{c|}{ Dif H/M } \\
\hline Partido & $\mathrm{N}$ & Média & Mediana & $\begin{array}{c}\text { Tempo } \\
(\mathrm{s})\end{array}$ & $\mathrm{N}$ & Média & Mediana & $\begin{array}{c}\text { Tempo } \\
(\mathrm{s})\end{array}$ & Dif/N & Dif/seg \\
\hline PSD & 116 & 15,8 & 13 & 1829 & 2 & 26,5 & 26,5 & 53 & $\mathbf{5 8 , 0}$ & $\mathbf{3 4 , 5}$ \\
\hline PTdoB & 18 & 4,7 & 5 & 85 & 1 & 13,0 & 13 & 13 & 18,0 & 6,5 \\
\hline
\end{tabular}




\begin{tabular}{|c|c|c|c|c|c|c|c|c|c|c|}
\hline PTB & 67 & 12,2 & 11 & 818 & 5 & 9,2 & 12 & 46 & 13,4 & 17,8 \\
\hline PRB & 24 & 9,9 & 9 & 237 & 2 & 10,0 & 10 & 20 & 12,0 & 11,9 \\
\hline PSC & 56 & 12,3 & 12 & 690 & 6 & 12,5 & 12,5 & 75 & $\mathbf{9 , 3}$ & 9,2 \\
\hline PPS & 50 & 8,8 & 5 & 442 & 6 & 5,3 & 5,5 & 32 & 8,3 & 13,8 \\
\hline PEN & 24 & 5,3 & 5 & 128 & 3 & 6,7 & 5 & 20 & 8,0 & 6,4 \\
\hline PMDB & 131 & 17,6 & 18 & 2305 & 18 & 18,0 & 18 & 324 & 7,3 & 7,1 \\
\hline PSDB & 108 & 16,9 & 13 & 1824 & 16 & 11,1 & 12 & 178 & 6,8 & 10,2 \\
\hline PRTB & 52 & 9,5 & 9 & 492 & 8 & 9,0 & 7,5 & 72 & 6,5 & 6,8 \\
\hline PV & 70 & 8,2 & 8 & 571 & 13 & 6,5 & 7 & 85 & 5,4 & 6,7 \\
\hline PSB & 181 & 6,7 & 5 & 1215 & 37 & 6,2 & 5 & 228 & 4,9 & 5,3 \\
\hline PCdoB & 18 & 24,0 & 25 & 432 & 5 & 7,6 & 8 & 38 & 3,6 & 11,4 \\
\hline PTC & 34 & 9,0 & 9 & 306 & 11 & 17,3 & 18 & 190 & 3,1 & 1,6 \\
\hline PDT & 44 & 9,7 & 10 & 428 & 16 & 10,1 & 10 & 162 & 2,8 & 2,6 \\
\hline PT & 151 & 10,8 & 10 & 1627 & 62 & 10,4 & 10 & 644 & 2,4 & 2,5 \\
\hline PRP & 35 & 11,4 & 11 & 398 & 16 & 11,8 & 12 & 188 & 2,2 & 2,1 \\
\hline PSOL & 27 & 8,4 & 7 & 226 & 13 & 7,9 & 7 & 102 & 2,1 & 2,2 \\
\hline PSDC & 37 & 6,0 & 5 & 221 & 20 & 4,6 & 4 & 91 & 1,9 & 2,4 \\
\hline PSL & 24 & 15,9 & 13 & 381 & 16 & 16,2 & 12,5 & 259 & 1,5 & 1,5 \\
\hline PPL & 3 & 7,3 & 7 & 22 & 4 & 8,3 & 8 & 33 & 0,8 & 0,7 \\
\hline PTN & 2 & 7,5 & 7,5 & 15 & 18 & 9,8 & 9,5 & 177 & 0,1 & 0,1 \\
\hline PCB & & & & & 18 & 32,9 & 34 & 592 & & \\
\hline PSTU & & & & & 18 & 30,8 & 30 & 554 & & \\
\hline PP & 76 & 20,7 & 25 & 1572 & & & & & & \\
\hline DEM & 55 & 17,8 & 15 & 979 & & & & & & \\
\hline PR & 43 & 14,0 & 12 & 600 & & & & & & \\
\hline PHS & 34 & 4,6 & 5 & 157 & & & & & & \\
\hline SD & 25 & 24,2 & 21 & 604 & & & & & & \\
\hline PMN & 21 & 5,0 & 5 & 104 & & & & & & \\
\hline PROS & 18 & 20,1 & 21,5 & 362 & & & & & & \\
\hline
\end{tabular}

A maior discrepância está no PSD em que há 116 segmentos para os homens e somente dois para mulheres, com uma diferença de 58 pontos entre os segmentos e 34,5 no tempo utilizado. Ou seja, a cada segmento que aparecia uma mulher, havia 58 para os homens. Neste caso, vale destacar que o partido só tinha duas candidatas e que deu a cada uma delas apenas uma oportunidade de aparecer na televisão. Os demais programas foram reservados para a presença dos homens, assim como todo o restante do tempo (1.829 segundos), sendo que o PSD era um dos partidos com mais tempo disponível.

A diferença também é significativa ao observar a distribuição entre os candidatos do PTB, em que para cada segmento destinado às mulheres, há 13,4 para homens. Entre os partidos maiores e com mais tempo de propaganda - como PSD, PSC, PMDB, PT, PSB e PP - também há diferenças: o PT e PSB são os que apresentam menores diferenças entre homens e mulheres quanto ao tempo e número de segmentos. O PT deu visibilidade para cinco mulheres e o PSB para seis. O restante são os que mais concentram as diferenças. Isso mostra que, apesar da semelhança entre as médias no tempo usadas por homens e mulheres, isso se dá de modo muito distinto entre os partidos, já que alguns dividem o tempo entre várias 
mulheres, outros concentram em apenas algumas e outros dão pouco tempo para poucas mulheres, mesmo tendo mais espaço disponível.

Esse dado também demonstra a tentativa de garantir visibilidade às mulheres em partidos de esquerda - como PCB e PSTU - ainda que eles possuam um tempo bastante restrito do HGPE, uma vez que obtiveram apenas aquele percentual do espaço dividido igualmente pelo TSE. Ambos os partidos optaram em usar todo o tempo para as mulheres, ainda que fosse apenas uma em cada partido. Já os mais sólidos, com exceção do PT e do PSB, há maiores diferenças entre os sexos.

Uma das formas de utilizar esse tempo disponível é por meio da fala em que, segundo Miguel (2010), os candidatos da disputa proporcional podem apresentar suas ações principais de modo rápido e fácil. O que ocorre é que alguns candidatos não possuem espaço de fala, havendo somente a sua imagem disponibilizada no HGPE. Portanto, pretende-se verificar se os homens e mulheres possuem espaços de fala na mesma proporção ou se neste quesito também há sub-representação da mulher na campanha, aparecendo na televisão, mas sem espaço para se comunicar diretamente com o eleitor. Para a análise, tem-se como ponto de partida a tabela abaixo que indica a relação entre sexo e presença de fala no HGPE.

Tabela 3 - Relação de segmentos com fala e sexo do candidato

\begin{tabular}{|c|c|c|c|c|}
\hline \multirow{3}{*}{ Ausência } & & Homem & Mulher & Total \\
\hline & $\mathrm{N}$ & 16 & 9 & 25 \\
\hline & $\mathrm{Rp}$ & -1 & 2,2 & \\
\hline \multirow[t]{3}{*}{ Presença } & $\mathrm{N}$ & 1528 & 325 & 1853 \\
\hline & $\mathrm{Rp}$ & 0,1 & $-0,3$ & \\
\hline & Total & 1544 & 334 & 1878 \\
\hline
\end{tabular}

Fonte: Grupo de Pesquisa em Comunicação Política e Opinião Pública (CPOP)

Os dados referentes ao qui-quadrado são significativos (sig 0,016), indicando que há diferenças na distribuição dos segmentos com e sem fala entre homens e mulheres. Nota-se uma predominância de segmentos com fala: 1.853 dos 1.878, o que equivale a 98,6\%. Esse é um valor, inclusive, bem acima dos 70\% encontrado por Cervi (2011) nas eleições de 2006. Isso mostra que os candidatos, de modo geral, estão tendo mais espaço durante a propaganda. Após observar esses dados gerais e o qui-quadrado ${ }^{7}$ significativo, é possível analisar os resíduos padronizados que vão indicar onde estão as relações de proximidade. Aqui nota-se que há uma concentração - ainda que dentro de um $\mathrm{N}$ pequeno - de casos de segmentos sem falas entre as mulheres, já que o resíduo é positivo de 2,2.

7 Os resíduos padronizados são complementares ao teste de qui-quadrado. Enquanto este último indica a relação entre as variáveis, os resíduos indicam a força de relação entre as categorias de cada variável. Os valores significativos dos resíduos são considerados quando estes são maiores que |+-1,96|. 
Percebe-se, portanto, no que diz respeito às falas, que esta característica é predominante, mas que quando há segmentos sem fala - apenas com a imagem do candidato isso tende a aparecer mais em casos de candidatas e não de candidatos, o que também leva a uma ideia de sub-representação da mulher na propaganda eleitoral. De modo a complementar a análise sobre a presença da mulher na propaganda nas eleições de 2014, observa-se como os segmentos de homens e mulheres apareceram ao longo da campanha, conforme a distribuição nos programas transmitidos pela televisão.

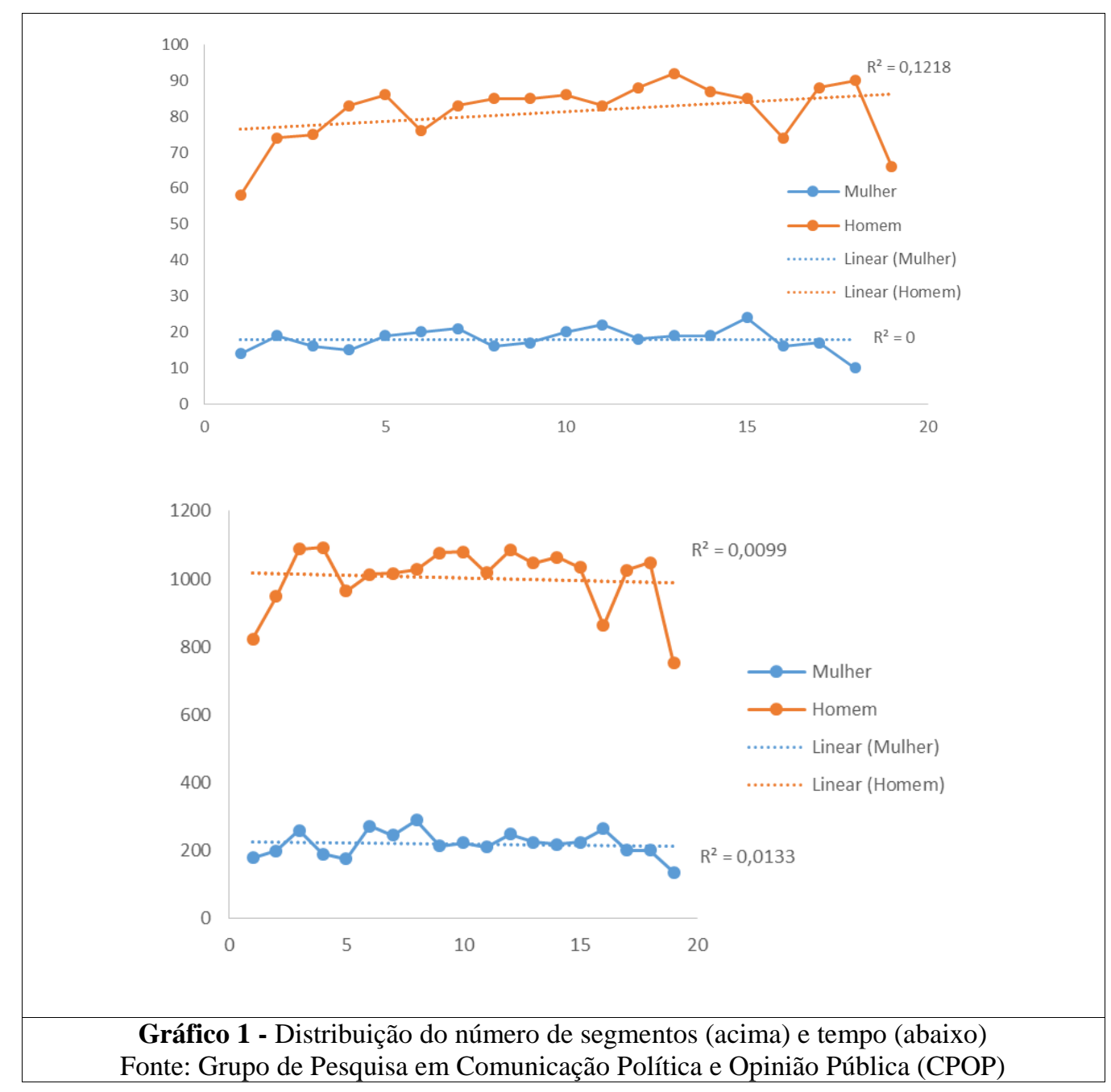

A literatura sobre HGPE indica que a audiência dos programas começa alta, perde espectadores durante o período intermediário e volta com mais força ao final, sendo uma curva em U (Cervi, 2011). Se as mulheres aparecem mais no momento intermediário supõe-se que, além de aparecerem menos que os homens, são destinados a elas os programas das datas em que não há audiência significativa. Já nos momentos de maior audiência, os candidatos ocupavam o espaço e, consequentemente, garantiam maior visibilidade no HGPE. Isso 
indicaria também a sub-representação feminina na propaganda eleitoral, já que os homens seriam vistos por uma quantidade maior de eleitores do que as mulheres.

O primeiro gráfico mostrou, no entanto, que há uma influência quase nula do tempo, com uma presença bastante similar entre homens e mulheres ao longo do período eleitoral. No caso dos homens há um leve aumento no final do período, como indica o $\mathrm{R}^{2}$ de 0,12 , o que significa que o tempo influencia em apenas $12 \%$ na presença dos candidatos, o que é algo pouco significativo. Do mesmo modo, para as mulheres a mudança em relação ao tempo é ínfima. Portanto, pelo menos em termos de quantidade de segmentos, não há aumento ao longo do tempo tão significativo a ponto de mostrar maior representatividade dos homens no período próximo à eleição e menos das mulheres, que se concentrariam no momento de menor audiência.

Já no segundo gráfico, a informação demonstrada é se houve aumento do tempo para homens e mulheres, uma vez que poderia haver segmentos mais longos para homens nos momentos de maior audiência, o que indicaria maior visibilidade perante o eleitorado e menor representação das mulheres. Ao que os dados mostram, o tempo também não tem alterações significativas mantendo-se sem grandes mudanças ao longo de todo o período.

Por fim, ao observar o tempo, espaço e média de tempo de cada uma das 58 mulheres que apareceram durante a propaganda eleitoral, verifica-se que apenas 12 delas obtiveram mais de um minuto (contados aqui em segundos) de aparição na televisão, ainda que seus partidos obtivessem mais tempo. Nove candidatas apareceram apenas uma vez ao longo dos 18 programas, 10 delas apareceram pelo menos duas vezes, e 26 apareceram entre 3 e 7 vezes. De todas as 58, apenas três delas apareceram em todos os programas: Christiane Yared (PTN), Mariane Siqueira (PSTU) e Prof. Silvina (PCB). Abaixo segue a tabela com as 12 candidatas que tiveram aparições que somaram mais de 1 minuto ao longo dos 18 programas.

Tabela 4 - Distribuição das mulheres com mais tempo de propaganda

\begin{tabular}{|c|c|c|c|c|c|}
\hline Nome & Partido & $\begin{array}{c}\text { Número de } \\
\text { Segmentos }\end{array}$ & Média & Mediana & Tempo \\
\hline Prof $^{\text {a Silvina }}$ & PCB & 18 & 32,89 & 34,00 & 592 \\
\hline Mariane Siqueira & PSTU & 18 & 30,78 & 30,00 & 554 \\
\hline Nair Lenz & PSL & 16 & 16,19 & 12,50 & 259 \\
\hline Telma Baggio & PRP & 16 & 11,75 & 12,00 & 188 \\
\hline Márcia Gracilia & PSDB & 16 & 11,13 & 12,00 & 178 \\
\hline Christiane Yared & PTN & 18 & 9,83 & 9,50 & 177 \\
\hline Jussara Joeckel & PTC & 10 & 17,20 & 18,50 & 172 \\
\hline Igle Maria & PT & 14 & 11,64 & 12,00 & 163 \\
\hline Professora Marlei & PT & 14 & 9,86 & 10,00 & 138 \\
\hline Sonia Brasileira & PMDB & 7 & 19,14 & 19,00 & 134 \\
\hline Janine Rodrigues & PMDB & 7 & 17,29 & 17,00 & 121 \\
\hline
\end{tabular}


PROGRAMA DE PÓS-GRADUAÇÃO EM COMUNICAÇÃO DA UNIVERSIDADE FEDERAL DE SANTA MARIA

\begin{tabular}{|c|c|c|c|c|c|}
\hline Toninha & PT & 12 & 10,00 & 10,00 & 120 \\
\hline Professora Rosa Maria & PT & 12 & 9,83 & 10,00 & 118 \\
\hline Cristina Felix & PT & 10 & 10,50 & 10,00 & 105 \\
\hline Marisa Lobo Psicóloga Cristã & PSC & 6 & 12,50 & 12,50 & 75 \\
\hline Prof. Elisabeth Schmidt & PSB & 11 & 6,45 & 5,00 & 71 \\
\hline Vera Dona de Casa & PMDB & 4 & 17,25 & 18,00 & 69 \\
\hline
\end{tabular}

Fonte: Grupo de Pesquisa em Comunicação Política e Opinião Pública (CPOP)

A partir dos dados acima se pode constatar que as mulheres com mais tempo no horário eleitoral são aquelas concentradas nos partidos que dedicaram todo o seu tempo às candidaturas femininas - como PCB e PSTU. Nair Lenz, por exemplo, era a única candidata do PSL e tinha um tempo semelhante ao dos homens, como a tabela 3 indicou. O PT tinha seis candidatas e cinco apareceram no HGPE, com melhor proporção em relação aos homens, ainda que algumas mulheres apareceram mais ao longo dos programas, como Igle Maria e Prof. Marlei. O PSDB tinha apenas uma candidata, porém era um dos partidos com maior espaço de propaganda e menos de 2 minutos foram destinados à sua candidata. Já a representante feminina do PTN, Christiane Yared, apareceu mais vezes do que os homens candidatos do partido - como mostrou a tabela 3. Apesar de haver mais uma candidata, somente esta apareceu e em todos os programas. O PTC tinha duas candidatas, mas somente uma delas se destacou em 10 programas.

Desta forma, os dados apresentados sugerem cinco considerações sobre a presença da mulher na propaganda eleitoral proporcional. O primeiro resultado mostra que, ainda que os partidos estejam próximos de cumprir a lei da proporcionalidade de cotas, há uma subrepresentação da mulher na propaganda televisiva: enquanto $27 \%$ das candidatas são mulheres, apenas $18 \%$ do tempo de TV é destinado a elas, sendo que algumas nem chegam a aparecer nos programas televisivos. Por outro lado, as mulheres que conseguem ganhar destaque possuem segmentos com tempo médio semelhante aos homens, o que garante, pelo menos a estas, maior representatividade.

Esses dados, apesar de demarcarem um padrão, não são assim em todos os partidos: alguns oferecem mais espaço às mulheres e outros menos. De um lado há partidos como PCB e PSTU que só deram espaço para mulheres, de modo estratégico, mas por outro há partidos que não deram visibilidade na propaganda televisiva para nenhuma candidata, como é o caso do DEM e do PP, que tinham tempo significativo na propaganda, mas distribuíram apenas entre candidatos, o que enfatiza aqui a sub-representação das mulheres de forma mais evidente nestes partidos.

Além dessa diferença partidária, as mulheres tendem a aparecer mais em segmentos sem fala - quando aparece só a imagem - não havendo espaço para mostrar suas demandas 
principais. No entanto, quando observada a mudança da presença ou ausência da mulher nos programas televisivos ao longo do tempo, a linha indica quase nenhuma alteração, seja para homens ou mulheres. Retomaremos os principais achados da pesquisa no tópico seguinte.

\section{CONSIDERAÇÕES FINAIS}

Os estudos sobre o conteúdo e estratégias do horário eleitoral para cargos proporcionais ainda são minoritários dentro da gama de pesquisas sobre o HGPE. Geralmente, o foco se dá nas campanhas majoritárias (Albuquerque, 1999; Dias, 2005; Borba, 2012). Quando se pretende discutir a presença das candidatas mulheres neste espaço, o leque diminui ainda mais. Os dois estudos recentes mais expressivos que fazem a diferenciação do tratamento entre homens e mulheres nos programas eleitorais são os de Miguel (2010) e Cervi (2011). Portanto, uma das finalidades deste artigo é contribuir com a perspectiva de entender as lógicas da campanha proporcional na TV, levando em consideração a presença feminina neste espaço.

Historicamente, a mulher é sub-representada nas instâncias políticas de poder, resultado de vários fatores sociais e institucionais, tais como a saída tardia da esfera privada e dupla jornada de trabalho (Walby, 1990; Araújo, 2001; Miguel, 2014; Sarmento, 2017), o sistema eleitoral e o tamanho do distrito (Araújo; Alves, 2007). Sacchet e Speck (2012) defendem ainda que o financiamento de campanha também é um fator que interfere no desempenho feminino nas eleições, já que as candidatas tendem a receber menos recursos do que os candidatos.

Para tentar minimizar as diferenças entre homens e mulheres no contexto políticoeleitoral, foi instituída a cota de gênero nas eleições brasileiras, em 1997, e que passou a ser obrigatória somente em 2009. Após quase 20 anos da instituição da lei, e de quase 10 anos de sua obrigatoriedade, o que se observa é que de fato houve aumento da participação feminina, conforme dados do Banco Mundial (2015), porém a representação nas instâncias legislativas ainda está longe de ser igualitária, estando o Brasil entre os piores colocados no ranking internacional, atrás de 154 países (Miguel, 2014; Sporh et al, 2016). O primeiro passo para que as mulheres alcancem cargos eletivos é terem condições de disputarem os pleitos. Idealmente isso deve ser feito no plano macrossocial, desconstruindo a sociedade patriarcal (Walby, 1990) e garantindo às mulheres igualdade nas relações de poder, tanto na esfera pública quanto na privada (Biroli, 2018). Já durante a campanha, é necessário que elas 
ganhem visibilidade nos programas eleitorais no rádio e TV tanto quanto os homens, pois o HGPE é importante para grupos que não possuem um nicho eleitoral geográfico (Albuquerque; Steibel; Carneiro, 2008) e, no caso específico das mulheres, tendem a depender mais da exposição de suas imagens, já que não conseguem se inserir em espaços anteriores à campanha (Massambani; Cervi, 2011; Biroli; Miguel, 2014). Dessa maneira, o que se pretendeu com esse artigo foi identificar o espaço que as candidatas mulheres tiveram na televisão durante a campanha para deputado federal do Paraná em 2014, traçando um comparativo com a presença masculina e com resultados anteriores, tais como os de Cervi (2011).

Os dados apresentados no artigo mostraram que, embora boa parte dos partidos esteja perto de cumprir a cota da proporcionalidade, que é de $30 \%$ e $70 \%$ para cada sexo, as candidatas ainda possuem menos tempo do que os candidatos. Do tempo total, as candidatas dividiram $18 \%$ do tempo, enquanto que os homens apareceram em $82 \%$. Ainda que haja essa diferença, quando as mulheres aparecem nas propagandas televisivas, possuem a mesma média de tempo do que seus concorrentes do sexo masculino, o que indica uma mudança quando comparada às eleições de 2006, em que Cervi (2011) concluiu que as mulheres têm participação menor do que deveriam na divisão do tempo, com exceção daquelas que já possuem mandato ou que ocupam cargos por indicação. No presente estudo, o papel que o candidato ocupa na disputa - candidato à reeleição, não ocupante de cargo eletivo ou sem mandato - não foi levado em consideração, mas serve como indicativo para pesquisas futuras, pois a distribuição dos recursos partidários também tende a variar conforme esse fator (Cervi, 2011).

Dentre os partidos que se destacam por incentivar a aparição feminina na televisão estão o PCB e o PSTU, que dedicaram todo o tempo que tinham para as candidatas; e o PT, onde as mulheres também tiveram boa aparição. Esses resultados reafirmam o que a literatura indica de que partidos mais à esquerda do espectro ideológico tendem a incentivar a maior participação feminina na política (Araújo; Alves, 2007) em relação aos de direita.

Outro aspecto que deve ser considerado é o tipo de aparição - com ou sem fala. O(a) candidato(a) pode aparecer com tempo maior, possibilitando "conversar" diretamente com o eleitorado; ou então apenas aparecer com o nome e número de votação, sem poder falar. No caso desse último, o tempo de exposição é bem baixo. A partir dos dados mostrados na análise percebeu-se que, de maneira geral, os candidatos de ambos os sexos possuem fala nos programas. No entanto, o teste do qui-quadrado assegura que as mulheres tendem a aparecer 
mais em segmentos sem fala, quando comparadas aos homens, o que seria prejudicial para sua visibilidade na campanha na TV.

Os resultados apresentados aqui não permitem fazer uma relação de causa e efeito no desempenho das mulheres nas eleições em função do HGPE, mas constata qual sua participação dentro da campanha televisiva, um dos espaços até então mais importantes da disputa brasileira. É uma das formas de alcançar visibilidade, sendo que o candidato ou candidata que aparecer mais tem maiores chances de ser reconhecido(a) e lembrado(a). A partir de uma aparição mais qualificada no horário eleitoral, as chances de passarem a ser conhecidas pelos eleitores aumentam, o que pode impactar na decisão do voto.

O que se observa, ainda, é que a sub-representação segue presente nas campanhas, desde o número de candidatas escolhidas pelos partidos - que muitas vezes não atinge o mínimo estabelecido pela cota de gênero - até o espaço de exibição no horário eleitoral desprendido a elas. Há mudanças em relação ao cenário de 2006 estudado por Cervi (2011), mas algumas diferenças seguem em destaque, como em relação aos partidos, por exemplo. A pesquisa indicou um cenário em que as mulheres que aparecem na televisão chegam a ter um tempo médio semelhante aos homens, embora haja diferenças entre os partidos, o que mostra que partido importa para medir a sub-representação. Espera-se, por fim, que esta pesquisa contribua com os achados sobre campanha proporcional e que abra novas possibilidades de investigação sobre a participação feminina nos espaços tradicionais de campanha enquanto candidatas.

\section{REFERÊNCIAS}

ALBUQUERQUE, Afonso de. Aqui você vê a verdade na tevê: a propaganda política na televisão. Rio de Janeiro: MCII/UFF, 1999.

ALBUQUERQUE, Afonso de. Propaganda política e eleitoral. In: RUBIM, Antonio (Org.). Comunicação e política: Conceitos e abordagens. Salvador: Edufba, 2004.

ALBUQUERQUE, Afonso de; STEIBEL, Fabro; CARNEIRO, Claudia. A outra face do horário gratuito: Partidos políticos e eleições proporcionais na televisão. DADOS - Revista de Ciências Sociais, v. 51, n. 2, p. 459-487. 2008.

ALBUQUERQUE, Afonso de; TAVARES, Camilla Quesada. Horário Gratuito de Propaganda Eleitoral: estilos, estratégia, alcance e desafios para o futuro. In: FIGUEIREDO, Argelina Cheibub; BORBA, Felipe (Orgs). 25 anos de eleições presidenciais no Brasil. Curitiba: Appris, 2018, p. 147170.

ARAÚJO, Clara. As cotas por sexo para a competição legislativa: o caso brasileiro em comparação com experiências internacionais. DADOS - Revista de Ciências Sociais, v. 44, n. 1, s/p. 2001. 
ARAÚJO, Clara. Partidos políticos e gênero: mediações nas notas de ingresso das mulheres na representação política. Revista de Sociologia e Política, n. 24, p. 193-215. 2005.

ARAÚJO, Clara; ALVES, José Eustáquio Diniz. Impactos de indicadores sociais e do sistema eleitoral sobre as chances das mulheres nas eleições e suas interações com as cotas. DADOS - Revista de Ciências Sociais, v. 50, n. 3, p. 535-577. 2007.

ARAÚJO, Clara; BORGES, Doriam. Trajetórias políticas e chances eleitorais: analisando o "gênero" das candidaturas em 2010. Revista de Sociologia e Política, v. 21, n. 46, p. 69-91. 2013.

BARBOSA, Tiago Alexandre Leme. Mulheres na elite partidária brasileira: uma análise exploratória das Comissões Executivas estaduais. Observatório de elites políticas e sociais do Brasil, v. 2, n. 10, p. 1-13. 2015.

BIROLI, Flávia. Gênero e desigualdades: limites da democracia no Brasil. São Paulo: Boitempo Editorial, 2018.

BORBA, Felipe. A propaganda negativa: estratégias e voto nas eleições brasileiras. 2012. 2012. Tese (Doutorado em Ciência Política) - Instituto de Estudos Sociais e Políticos, Universidade do Estado do Rio de Janeiro, Rio de Janeiro.

CERVI, Emerson. Métodos quantitativos nas ciências sociais: uma abordagem alternativa ao fetichismo dos números e ao debate com qualitativistas. In: BOURGUIGNON, Jussara Ayres (Org.) Pesquisa Social: reflexões teóricas e metodológicas. Ponta Grossa: TODAPALAVRA Editora, 2009. p. 125-143.

CERVI, Emerson. O "tempo da política" e a distribuição dos recursos partidários: uma análise do HGPE”. Em Debates, v. 2, n. 8, p. 12-17. 2010.

CERVI, Emerson. O uso do HGPE como recurso partidário em eleições proporcionais no Brasil: um instrumento de análise de conteúdo. Opinião Pública, v. 17, n, 1, p. 106-136. 2011.

DIAS, Marcia. Projeção da imagem partidária nas estratégias de campanha na televisão: uma análise do HGPE 2002. DADOS - Revista de Ciências Sociais, v. 48, n. 1, p. 149-187. 2005.

FIGUEIREDO, Marcus; ALDÉ, Alessandra; DIAS, Heloisa; JORGE, Vladimyr L. Estratégias de persuasão eleitoral: uma proposta metodológica para o estudo da propaganda eleitoral. Opinião Pública, v. IV, n. 3, p. 182-2013. 1997.

HOLTZ-BACHA, Christina; JOHANSSON, Bengt; LEIDENBERG, Jacob; MAAREK, Philippe J.; MERKLE, Susanne. Advertising for Europe TV Ads During the 2009 European Election Campaign in Four Countries. Nordicom Review, v. 33, n.2, p.77-99. 2012.

LIMA, Bárbara; ALVES, Mércia . O Partido dos Trabalhadores: Um perfil do investimento financeiro nos meios de comunicação de massa nas eleições. Aurora (PUCSP. Online), v. 7, p. 66-80, 2015.

MARTINS, Eneida Valarini. A política de cotas e a representação feminina na Câmara dos Deputados. 2007. Monografia (especialização) - Centro de Formação, treinamento e aperfeiçoamento (Cefor), da Câmara dos Deputados, Curso de Especialização em Instituições e Processos Políticos do Legislativo.

MASSAMBANI, Ana Cláudia; CERVI, Emerson. A participação das mulheres no HGPE proporcional: uma análise comparativa das campanhas para deputado federal no Paraná em 2006 e 
2010. In: XII CONGRESSO DE CIÊNCIAS DA COMUNICAÇÃO NA REGIÃO SUL. Londrina, 2011.

MIGUEL, Luis Felipe. Televisão e construção da agenda eleitoral no Brasil. Diálogos latinoamericanos, n. 10, p. 1-16. 2005.

MIGUEL, Luis Felipe. Apelos discursivos em campanhas proporcionais na televisão. Política e Sociedade, v. 9, n. 16, p. 151-175. 2010.

MIGUEL, Luis Felipe. Gênero e representação política. In: MIGUEL, Luis Felipe; BIROLI, Flávia. Feminismo e política. São Paulo: Boitempo, 2014. p. 17-30.

MIGUEL, Luis Felipe; BIROLI, Flávia. Feminismo e política. São Paulo: Boitempo, 2014.

NORRIS, Pippa. Recrutamento político. Revista Sociologia e Política, v. 21, n. 46, p. 11-32. 2013.

PANKE, Luciana; CERVI, Emerson. Análise da comunicação eleitoral: uma proposta metodológica para os estudos do HGPE. Contemporânea - Comunicação e Cultura, v. 9, n. 3, p. 390-404. 2011.

SACCHET, Teresa; SPECK, Bruno Wilhelm. Financiamento eleitoral, representação política e gênero: uma análise das eleições de 2006. Opinião Pública, v. 18, n. 1, p. 177-197. 2012.

SARMENTO, Rayza. Representação descritiva comprometida com o desenvolvimento das mulheres: quais critérios importam? Novos Cadernos NAEA, v. 20, n. 3, p. 81-96, 2017.

SPOHR, Alexandre Piffero; MAGLIA, Cristiana; MACHADO, Gabriel; OLIVEIRA, Joana Oliveira de. Participação política de mulheres na América Latina: o impacto de cotas e de lista fechada. Estudos Feministas, vol. 24, n. 2, p. 417-441, maio-agosto. 2016.

VIEGAS, José Manoel Leite; FARIA, Sérgio. Participação política femininas: percursos, constrangimentos e incentivos. Sociologia - Problemas e práticas, n. 30, p. 66-87. 1999.

WALBY, Sylvia. Theorizing patriarchy. Oxford: Blackwell, 1990. 
Camilla Quesada Tavares

Professora adjunta do curso de Comunicação Social - Jornalismo e do Programa de Pós-Graduação em Comunicação da Universidade Federal do Maranhão (UFMA/Imperatriz). Doutora em Comunicação pela Universidade Federal Fluminense (PPGCOM/UFF). Coordenadora do grupo de pesquisa em Comunicação, Política e Sociedade (COPS).

Michele Goulart Massuchin

Professora adjunta do Departamento de Comunicação e do Programa de Pós-Graduação em Comunicação e Ciência Política da Universidade Federal do Paraná (UFPR). Doutora em Ciência Política pela Universidade Federal de São Carlos (UFSCar). Pesquisadora do grupo de pesquisa em Comunicação Política e Opinião Pública (CPOP).

\section{@ $\odot \Theta \odot$}

Esta obra está licenciado com uma Licença

Creative Commons Atribuição-NãoComercial-CompartilhaIgual 4.0 Internacional 